\title{
$\mathrm{BIM}$ 과 GIS간 정보상호운용을 위한 외부 $\mathrm{BIM}$ 참조 모델 제안
}

\section{The External BIM Reference Model Suggestion for Interoperability Between BIM and GIS}

\author{
강 태 욱 ${ }^{*}$ 홍 창 희 ${ }^{* *}$ 황 정 래 ${ }^{* * *}$ 최 현 상 ${ }^{* * * *}$ \\ Tae Wook Kang Chang Hee Hong Jung Rae Hwang Hyun Sang Choi
}

\begin{abstract}
요 약 본 연구는 $\mathrm{BIM}$ 과 GIS간 상호운용성을 위해 외부 $\mathrm{BIM}$ 참조 모델을 제안한다. 이를 위해 $\mathrm{BIM}$ 과 GIS간 상호운용성과 관련된 연구 현황과 유즈케이스들을 조사하였다. 그리고 이러한 상호운용성 지원을 위한 CityGML 모델 확장을 위해 IFC와 CityGML의 구조를 분석하였다. 이런 결과를 바탕으로 $\mathrm{IFC}$ 로부터 CityGML로 맵핑하는 규칙을 정의한 메타 데이터를 포함한 외부 $\mathrm{BIM}$ 참조 모델을 제안하였다.
\end{abstract}

키워드 : IFC, CityGML, 상호운용성, 메타데이터, 맵핑, 참조 모델

\begin{abstract}
The purpose of the present study is to suggest the extern BIM reference model for interoperability between BIM and GIS. After we surveyed the research progress and usecases related to the interoperability to do this, we analyzed the architecture of the neutral model such as IFC, CityGML to identify the differences between these and expand CityGML model. By using this result, we proposed the external BIM reference model including the metadata which defines mapping rules from IFC to CityGML.
\end{abstract}

Keywords : IFC, CityGML, Interoperability, Metadata, Mapping, Reference model

\section{1. 서 론}

최근 시설물 관리, 인허가 법규 검토, GIS 정보를 활용한 다양한 분석 및 시공 시뮬레이션 등 건축 모델링시 GIS를 연계한 유즈케이스 실행의 필요성 이 증가되고 있다. 이런 유즈케이스는 BIM 과 GIS 모델을 사용한 정보 쿼리 시 상호운용성을 필요로 하고, 이를 위해서 두 정보모델간의 참조 관계를 효 과적으로 지원해야 한다. $\mathrm{BIM}$ 정보는 $\mathrm{LOD}($ Level Of Detail) 4 이상의 정보량이 포함되므로 이를 기존 GIS 플랫폼에 띄우면, 성능이나 리소스 관리 등 여 러 가지 문제가 발생한다.

해결 방안을 얻기 위해 이와 관련된 연구 동향을 조사한 후 BIM과 GIS간의 상호운용성과 관련된 유 즈케이스를 고찰하고 각 분야의 대표적인 중립 모
델인 IFC(Industry Foundation Class)와 CityGML 의 구조적 특징과 공통 구조를 고찰한다. 이 후 이 런 문제에 대한 다른 접근법으로 메타데이타를 이 용한 외부 $\mathrm{BIM}$ 참조 모델을 제안한다.

\section{BIM-GIS 간 상호운용성 연구 동향}

$\mathrm{BIM}$ 과 GIS 중립 모델간의 관련 국내연구는 주로 GIS에서 건축모델을 추출하고 활용하는 관점에서 접근되고 있다. 이와 관련해 건물에 대한 $3 \mathrm{D} \mathrm{GIS}$ 를 구축하기 위한 기초자료를 효율적으로 획득하는 방 법을 $\mathrm{BIM}$ 모델에서 추출하는 방법이 연구되었으며 [7], 유비쿼터스 도시 운영과 관련해 GIS기술과 OGC(Open Geospatial Consortium)기술을 통합하 여 시설물을 관리하는 방안에 대한 연구가 있었

\footnotetext{
† 본 연구는 한국건설기술연구원의 '(12주요)BIM/GIS 플랫폼기반 건설공간정보 통합운영기술 개발과제의 연구성과입니다.

" 한국건설기술연구원 ICT융합연구실 수석연구원 ktw@kict.re.kr

" 한국건설기술연구원 ICT융합연구실 수석연구원 chhong@kict.re.kr

*.* 한국건설기술연구원 ICT융합연구실 수석연구원 jrhwang@kict.re.kr

한국건설기술연구원 ICT융합연구실 연구위원 hyunsang@kict.re.kr(교신저자)
} 
다.[8] 김이두는 IFC로 부터 건물상세모델을 구축하 고, 3차원 지형을 포함한 3D GIS용 캠퍼스 모델을 구축하였다.[9]

해외에서는 IFC데이터에서 GML데이터로 변환하 는 방법 및 <그림 $1>$ 과 같은 변환 도구 개발에 대 한 연구가 진행되었으며, <그림 2>와 같이 건물 상 수도 네트워크 분석 및 관리와 관련하여 $\mathrm{IFC}$ 에서 CityGML로 정보를 추출해 적용한 사례 연구가 있 었다.[3, 4]

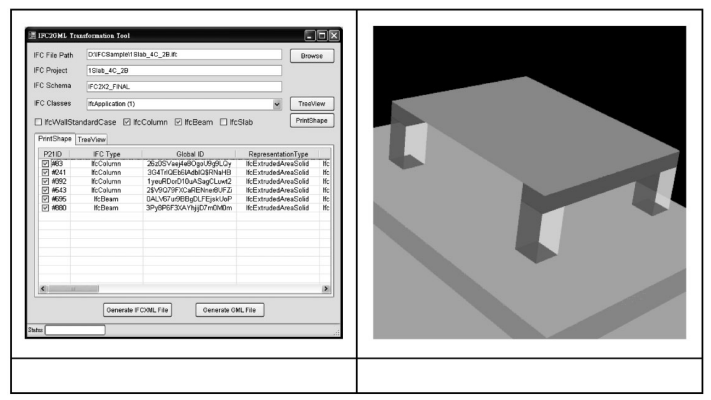

그림 1. IFC2GML[3]

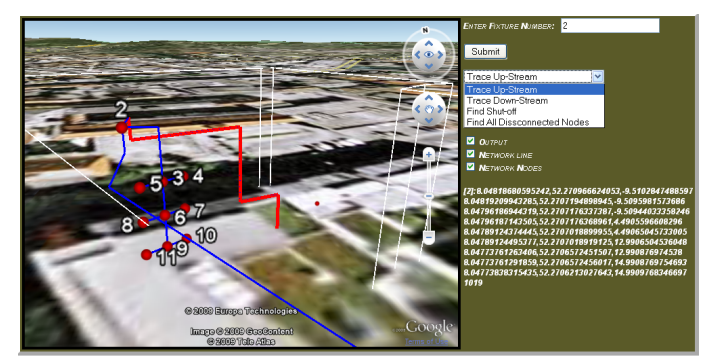

그림 2. Water Utility network application[4]

이외에 CityGML을 확장한 GeoBIM 모델 개발에 대한 연구가 있었고 CityGML과 IFC모델에 관한 차이를 기술하고 <그림 $3>$ 과 같이 모델 확장 방안 을 제안하였다.[5]

지금까지는 GIS에 건물을 표현하기 위해 City $\mathrm{GML}$ 모델을 이용하고, 확장 시 필요한 정보는 $\mathrm{IFC}$ 에서 형상과 속성정보를 변환해 CityGML로 변환하 는 것에 관한 연구가 대부분이다. 이러한 연구는 CityGML 모델 스키마로 IFC를 변환할 때 어느 정 도 정보 손실이 있으며, 변환된 파일 크기가 10 배 이상 증가하며[5], IFC모델이 업데이트될 때 다시 변환해 줘야 하는 등의 문제가 발생한다. 본 연구에 서는 이와는 다른 관점에서 외부 $\mathrm{BIM}$ 모델을 참조 함으로써 이런 문제를 해결하는 방안을 연구해 본다.

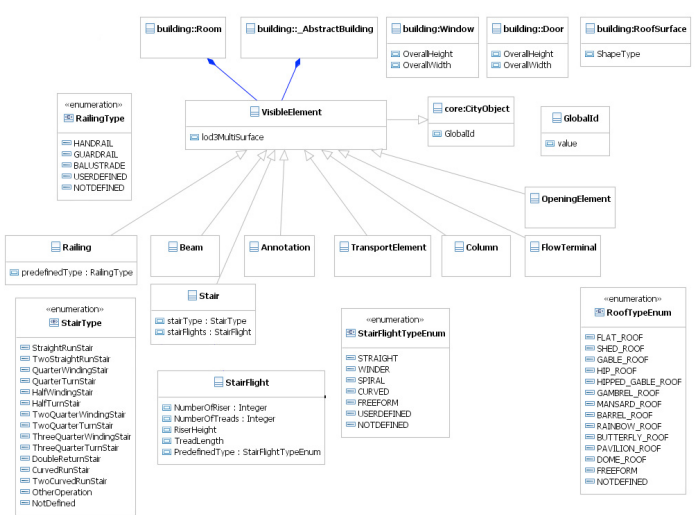

그림 3. The GeoBIM extension (ADE) for CityGML[5]

\section{BIM-GIS 간 상호운용성과 모델 특징}

\subsection{BIM-GIS간 상호운용성 특징}

상호운용성은 특정 객체에 대해 정보를 바라보는 관점이 다른 이해당자들 간 정보 교환이 필요할 때 발생한다. BIM-GIS간 정보 상호운용은 건설 프로 세스 단계별 이해당사자간의 정보교환 필요성에 의 해 발생하며, 현황 조사, 토목 엔지니어링은 GIS정 보 활용 중심인 유즈케이스이고, 건물 디자인, 건물 시설물 관리는 BIM정보 활용 중심인 유즈케이스이 다. 각 유즈케이스를 수행하기 위해서는 서로간의 정보교환이 필요하다. 내용은 다음 그림과 같다.

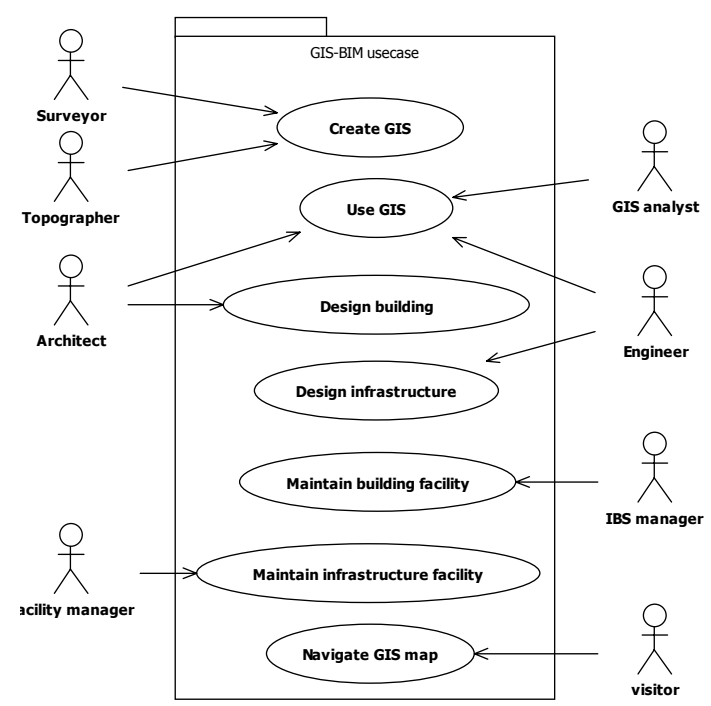

그림 4. GIS-BIM 유즈케이스 다이어그램 
아래는 이와 관련된 시나리오 기술이다.

표 1. GIS-BIM 유즈케이스 기술

\begin{tabular}{|c|c|c|}
\hline 액터 & 유즈케이스 & 기술 \\
\hline Surveyor & Create GIS & $\begin{array}{l}\text { GIS 정보를 조사/측정하고 } \\
\text { 구조화한다. }\end{array}$ \\
\hline Architect & Use GIS & $\begin{array}{l}\text { 건축가는 대지나 도로와 같 } \\
\text { 은 인프라스트럭쳐, 주변 } \\
\text { 환경을 고려한 건물 디자인 } \\
\text { 을 위해, GIS 정보를 활용 } \\
\text { 한다. }\end{array}$ \\
\hline $\begin{array}{c}\text { GIS } \\
\text { analyst }\end{array}$ & $\begin{array}{l}\text { Use GIS } \\
\text { map }\end{array}$ & $\begin{array}{l}\text { GIS 분석가는 분석에 필요 } \\
\text { 한 정보를 추출하기 위해 } \\
\text { GIS 정보를 사용한다. }\end{array}$ \\
\hline Architect & $\begin{array}{l}\text { Design } \\
\text { building }\end{array}$ & $\begin{array}{l}\text { 발주자 요구에 맞는 형상, } \\
\text { 위상, 속성을 포함한 건물 } \\
\text { 정보 모델을 디자인한다. }\end{array}$ \\
\hline Engineer & $\begin{array}{l}\text { Use GIS } \\
\text { map }\end{array}$ & $\begin{array}{l}\text { 엔지니어는 GIS 정보에서 } \\
\text { 인프라스트럭쳐 디자인에 } \\
\text { 필요한 정보를 사용한다. }\end{array}$ \\
\hline Engineer & $\begin{array}{l}\text { Design } \\
\text { infrastructure }\end{array}$ & $\begin{array}{l}\text { 지형정보, 환경, 지하시설물 } \\
\text { 과 같은 GIS정보를 활용해 } \\
\text { 인프라스트럭쳐를 디자인한 } \\
\text { 다. }\end{array}$ \\
\hline $\begin{array}{c}\text { IBS } \\
\text { manager }\end{array}$ & $\begin{array}{l}\text { Maintain } \\
\text { building } \\
\text { facility }\end{array}$ & $\begin{array}{l}\text { 건물 내 시스템, 시설물, 조 } \\
\text { 명과 같은 Fixture를 에너 } \\
\text { 지 효율적으로 유지관리한 } \\
\text { 다. }\end{array}$ \\
\hline $\begin{array}{l}\text { Facility } \\
\text { manager }\end{array}$ & $\begin{array}{c}\text { Maintain } \\
\text { infrastructure } \\
\text { facility }\end{array}$ & $\begin{array}{l}\text { 인프라스트럭쳐 시설물을 유 } \\
\text { 지관리한다. }\end{array}$ \\
\hline visitor & $\begin{array}{c}\text { Navigate GIS } \\
\text { map }\end{array}$ & $\begin{array}{l}\text { GIS 정보를 이용해 경로나 } \\
\text { 관련 정보를 탐색한다. }\end{array}$ \\
\hline
\end{tabular}

이외에도 Field BIM과 같이 현장 관리를 위한 $\mathrm{BIM}$ 기술은 위치기반의 GIS 정보의 도움을 받아야 한다.

\subsection{IFC 특징}

$\mathrm{BIM}$ 대표적 중립 모델인 $\mathrm{IFC}$ 에는 빌딩스마트가 전 생명 주기 동안에 필요한 건축 모델 정보를 객 체지향적인 개념에 따라 개발하여 구조화하였으며, 초기의 릴리즈는 Architectural Design, HVAC Engineering Design, Facilities Management, 및 Cost Estimating 안에서의 프로세스를 지원하는 모 델을 포함하고 있으나, 프로젝트 모델 범위 중 일 부분만을 표현하고 있어 초기 릴리즈에 대한 보완 사항이 요구되었고, IFC 2.0부터는 IFC Object Model의 도메인 범위를 확장하고, 건축, 견적, $\mathrm{FM}$,
설비, 법규 등 도메인 프로세스가 포함되었다. IFC 는 건축 모델링, 견적, 시설물 관리 소프트웨어가 특정 프로그램과 상관없이 $\mathrm{BIM}$ 모델로부터 각종 데이터의 추출 및 분석이 가능해 지는 것을 목표로 한다. 현재 $\mathrm{IFC} 2 \mathrm{X} 4$ 의 개발이 진행되고 있다.

국내에서는 2008년 4월 한국빌딩스마트협회가 출 범하며 국내에서 본격적으로 $\mathrm{IFC}$ 가 활용되기 시작 하였다. 특히 지난 2010년에는 IFC 포맷으로 결과 물을 제출해야 하는 Open BIM 기반으로 진행된 최 초의 현상설계 프로젝트인 전력거래소 현상설계 프 로젝트가 발주되었으며, 앞으로도 $\mathrm{IFC}$ 포맷을 표준 포맷으로 하는 다양한 프로젝트가 발주될 것으로 예상된다. 또한 지난 2006년부터 2011년까지 국토해 양부 건설기술혁신사업의 일환으로 진행된 가상건 설 시스템 개발 연구단에서는 건설 프로젝트 참여 주체 간에 원활한 $\mathrm{BIM}$ 정보 교환을 위하여 $\mathrm{CPLM}$ (Construction Project Lifecycle Management)를 개 발하였고, 이와 관된 $\mathrm{IFC} \mathrm{ORDB}$ 서버가 개발되었 다. 지난 2011년에는 IFC기반 모델링 솔루션 개발 과 관련된 World Best Software 과제가 발주되는 등 업계 뿐 만이 아니라 학계에서도 지속적인 연구 가 이루어지고 있다.

$\mathrm{IFC}$ 의 구조적 특징은 다음과 같다.

\section{2 .1 객체지향적 구조}

$\mathrm{IFC}$ 는 객체지향적인 구조로 개발되어 클래스가 패 키지로 묶여져 있으며, Kernel 패키지를 Extension패 키지가 객체지향적으로 파생 받아 활용하는 식으로 계층적 구조를 가지고 있다.

\section{2 .2 유연한 객체 관계성}

$\mathrm{IFC}$ 객체 간 관계는 속성으로 미리 정의되어 있지 않고, 그림 4와 같이 IfcObjectDefinition이 IfcRel*로 시작되는 클래스 관계(Relationship)를 관리한다. 이 런 이유로 유연한 클래스 간 관계처리가 가능해진 반면에, 모델러가 클래스 관계를 생성하는 방식에 따라 서로 다른 버전의 $\mathrm{IFC}$ 파일이 생성되므로, 모 델 간에 호환성 문제가 발생할 수 있다.

\section{2 .1 확장성있는 속성 구조}

$\mathrm{IFC}$ 는 그림 5 와 같이 확장성 있는 속성구조를 가 지고 있다. 속성은 IfcPropertySet에서 관리하는 데 IfcPropertyResource 패키지에 정의된 IfcProperty 클 래스를 가진다. IfcProperty는 정수, 실수와 같은 단 


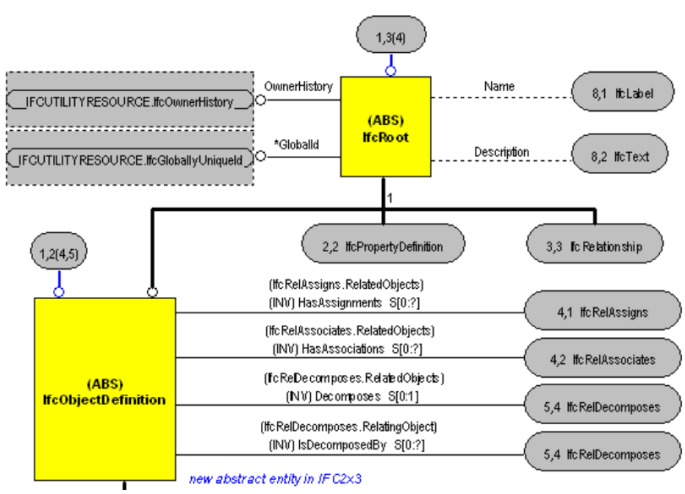

그림 5. IfcObjectDefinition 클래스와

Relationship(EXPRESS-G, IFC 2x4, BuildingSmart [2])

일 값이나 행렬과 같은 테이블 값, 리스트 형태 값 및 이와 같은 속성 값이 복합적으로 적용된 값과 같은 속성을 다룰 수 있다. 벽체와 같은 건축 요소 들은 여러 개 범주로 IfcPropertySet을 가질 수 있 으며, 이 객체는 IfcObjectDefinition에서 파생받은 IfcTypeObject에서 관리한다.

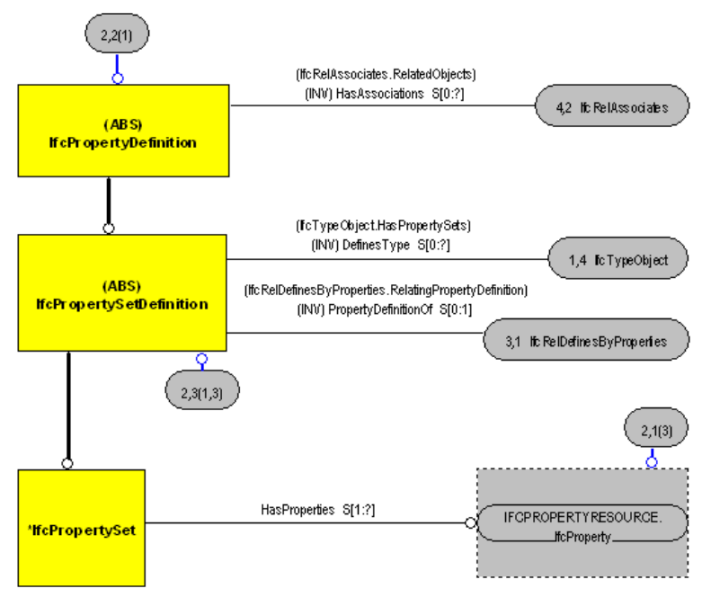

그림 6. IfcPropertySet 구조(EXPRESS-G, IFC 2x4, BuildingSmart [2])

\subsection{4 솔리드 모델 표현}

$\mathrm{IFC}$ 는 B-Rep 솔리드 모델 구조로 물체를 표현한 다. 솔리드는 크게 위상정보와 형상정보로 나뉘는 데, 위상정보는 아래 그림과 같이 형상을 구속하는 Vertex, Edge, Loop, Face로 구성되며, 형상은 곡선 및 곡면을 수학적으로 표현할 수 있는 매개변수로 구성되며, 형상은 다양한 종류의 곡선이나 곡면으로
표현할 수 있다. 이런 구조로 인해, 곡면 요소도 평 면으로 나누어 조합하는 방식으로 형상을 처리할 수 있으므로 이에 따라 수량이 원본 모델과 차이가 발생할 수도 있다.

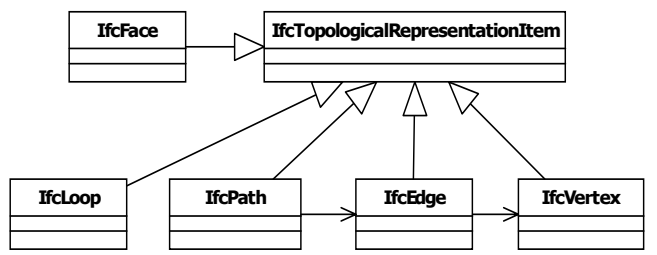

그림 7. IFC 위상정보(UML)

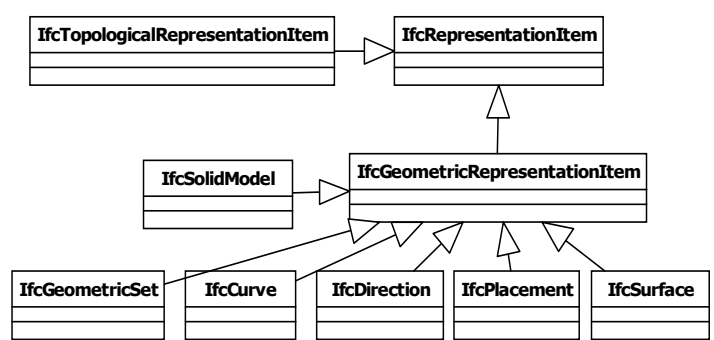

그림 8. IFC 형상정보(UML)

이런 솔리드 모델 구조를 이용해 표현된 벽체와 같은 건축요소는 다음 그림처럼 표현된다.

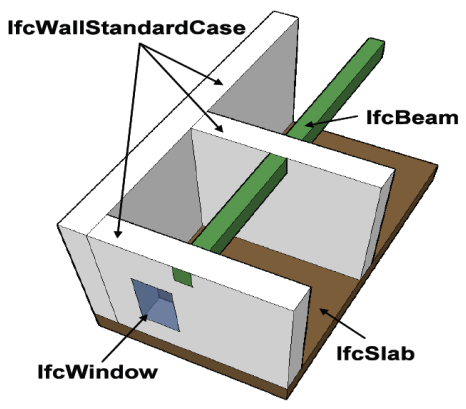

그림 9. IFC 형상 표현[6]

$\mathrm{IFC}$ 모델은 소프트웨어 개발 회사 간의 이해 관 계를 비롯하여 다양한 이유에서 최근의 IFC 발전은 $\mathrm{IFC} 2 \mathrm{X} 3$ 이후로 정체된 상황이다. 이런 구조적 특 징으로 인해 범용적인 포맷이 되었으나, 반면에 $\mathrm{BIM}$ 소프트웨어 별로 동일한 유형의 $3 \mathrm{D}$ 객체의 형 상을 표현하는 방법이 서로 다름에 따라 IFC $2 \mathrm{X} 3$ 체계 하에서 모델러 간 호환성이 결여되거나 오류 가 발생하고 있다. 


\subsection{CityGML 특징}

CityGML은 OGC에서 개발하는 GIS 기반 개방형 객체 정보 모델이며, 도시 객체 모델 정보 상호운용 성을 위한 포멧으로 $\mathrm{GML}$ 기반 응용스키마이다. CityGML은 GML에서 부족한 모델을 보강하여 3차 원 공간모델링을 보다 효율적으로 하기 위해 개발 이 되었다. CityGML의 구조적 특징은 다음과 같다.

\subsubsection{Surface 구조}

CityGML에서 형상은 다음 그림과 같이 형상, 재 질, 객체(feature) 모델 및 그들 간의 위상적 관계로 정의된다.

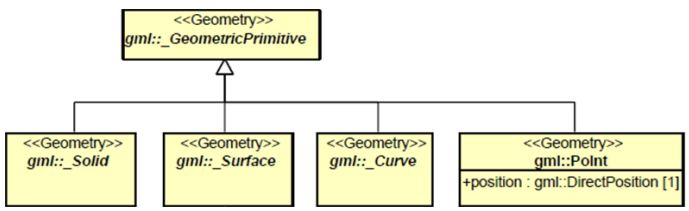

그림 10. CityGML 구조(Geometry 예)[1]

CityGML의 형상은 표면으로 정의되며, 예를 들 어 벽체와 같은 경우 아래 그림과 같이 내벽면, 외 벽면으로 표현되게 된다.

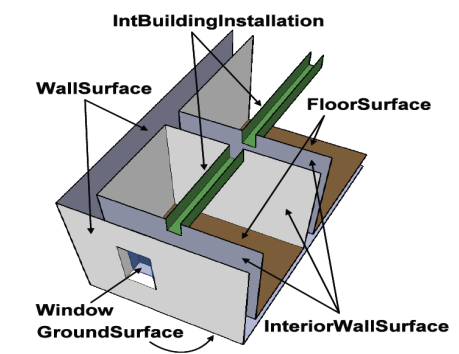

그림 11. CityGML 형상 표현[6]

이는 채워진 솔리드 모델로 표현되는 $\mathrm{IFC}$ 와는 차 이가 있다.

\subsubsection{LOD 구조}

형상은 모델의 추상화와 처리 성능을 고려해 다 음 그림과 같이 $\mathrm{LOD}($ Level Of Detail) 방식으로 정 보를 표현하고 있다. 이는 거리에 따른 정보 가시화 를 통한 추상화와 처리 성능을 고려한 방식이다.

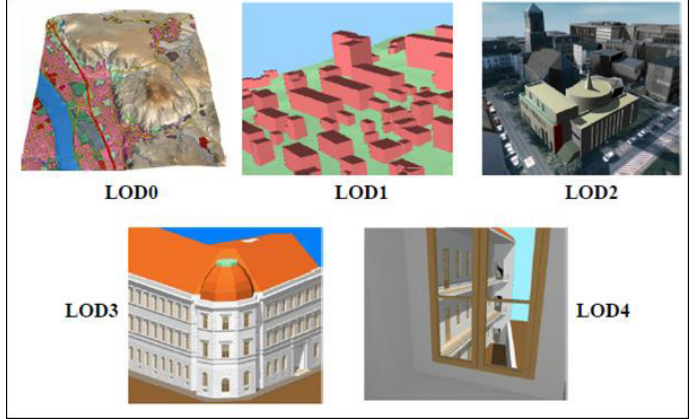

그림 12. LOD 표현방식(CityGML, OGC)[1]

\subsection{3 확장성 있는 객체 구조}

객체 모델은 다음 그림과 같으며, gml::_Feature를 기본 클래스로 하여, CityModel이_CityObject를 Composite pattern 으로 관리하고 있어, 확장성을 고려하고 있다.

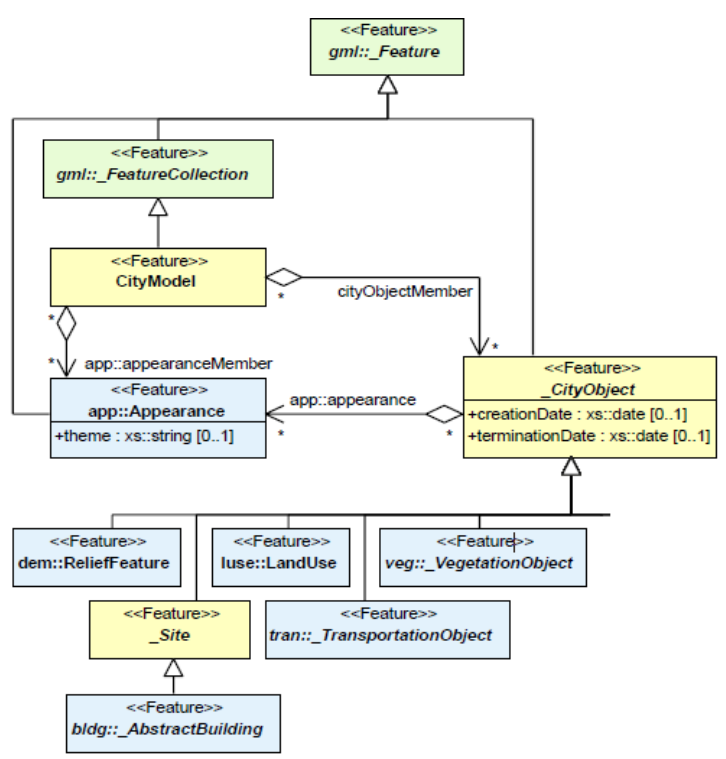

그림 13. CityGML(OGC)[1]

\subsection{IFC와 CityGML 비교}

아래는 앞서 분석한 IFC와 CityGML구조를 바탕 으로 차이점을 나타낸 표이다. 
표 2. $\mathrm{IFC}$ 와 CityGML 차이점 분석

\begin{tabular}{|c|c|c|}
\hline 구분 & IFC & CityGML \\
\hline $\begin{array}{l}\text { 객체 } \\
\text { 구조 }\end{array}$ & $\begin{array}{l}\text { 건축 중심으로 수량과 } \\
\text { 견적이 가능한 정도로 } \\
\text { 자세한 객체 구조를 가 } \\
\text { 짐 }\end{array}$ & $\begin{array}{l}\text { 도시 객체를 중심으로 } \\
\text { 처리 성능을 고려한 대 } \\
\text { 규모 } 3 \mathrm{D} \text { 객체 가시화 } \\
\text { 및 객체 확장 용이한 } \\
\text { 구조 }\end{array}$ \\
\hline LOD & $\begin{array}{l}\text { 형상 모델로부터 정확 } \\
\text { 한 도면, 수량이나 물 } \\
\text { 성을 추출하는 방법을 } \\
\text { 고려하여, LOD방식은 } \\
\text { 고려하지 않음 }\end{array}$ & $\begin{array}{l}\text { 형상 추상화에 따른 처 } \\
\text { 리 성능을 고려하여 } \\
\mathrm{LOD} \text { 수준에 따른 형상 } \\
\text { 을 관리 }\end{array}$ \\
\hline $\begin{array}{l}\text { 형상 } \\
\text { 표현 }\end{array}$ & $\begin{array}{l}\text { 채워진 솔리드 모델 방 } \\
\text { 식 }\end{array}$ & Surface방식 \\
\hline $\begin{array}{l}\text { 지원 } \\
\text { 객체 }\end{array}$ & $\begin{array}{l}\text { 지형모델이나 도로와 } \\
\text { 같은 부분을 제외한 대 } \\
\text { 부분의 건축요소지원 }\end{array}$ & $\begin{array}{l}\text { 지형, 도로와 같은 인 } \\
\text { 프라스트럭쳐는 지원하 } \\
\text { 나 세부 건축요소들은 } \\
\text { 지원하지 않음 }\end{array}$ \\
\hline
\end{tabular}

\section{IFC 참조 모델}

\section{1 고려사항}

앞서 언급한 바와 같이 지금까지 연구들은 대부 분 CityGML에서 AbstractBuilding을 확장하거나, 기존의 IFC모델 중 형상정보를 추출하여 CityGML $\mathrm{LOD}$ 수준에 따라 맵핑하는 방식으로 상호운용성을 접근하였다. 이런 방식은 다음 표와 같은 이슈를 가 져온다.

표 3. 맵핑 방식의 상호운용성 이슈

\begin{tabular}{|c|c|}
\hline 구분 & 내용 \\
\hline $\begin{array}{l}\text { 정보 } \\
\text { 손실 }\end{array}$ & $\begin{array}{l}\text { IFC에서 CityGML 모델 스키마로 정보 변환 } \\
\text { 시 서로 모델 구조가 다름. } \\
\text { 이로 인해 정보 손실이나 차이가 발생할 수 } \\
\text { 있음. }\end{array}$ \\
\hline $\begin{array}{l}\text { 파일 } \\
\text { 크기 }\end{array}$ & $\begin{array}{l}\text { 일반적으로 IFC는 Text기반 중립 포맷이므 } \\
\text { 로, Revit과 같은 모델러에서 저장하였을 경 } \\
\text { 우 } 10 \text { 배 이상 크기가 증가하는 문제가 있음. } \\
\text { 이대로 IFC에서 CityGML로 변환하였을 경 } \\
\text { 우 CityGML 모델 활용이 어려울 수 있음. }\end{array}$ \\
\hline $\begin{array}{l}\text { 오버 } \\
\text { 헤드 }\end{array}$ & $\begin{array}{l}\text { IFC모델이 업데이트될 때 다시 변환해 줘야 } \\
\text { 하는 문제가 발생. } \\
\text { DBMS처럼 데이터를 넣어준 후에 정보 쿼리 } \\
\text { 만 할 경우에는 큰 문제가 되지 않으나, 엔 } \\
\text { 지니어링과정에서 IFC 정보가 빈번하게 수정 } \\
\text { 될 경우 CityGML과 동기화를 위한 변환작 } \\
\text { 업에 오버헤드가 있음. }\end{array}$ \\
\hline
\end{tabular}

\subsection{IFC 참조 모델 제안}

이러한 부분을 고려해, 모든 IFC정보를 CityGML
로 변환할 것이 아니라, CityGML에서 정보 쿼리 시 $\mathrm{IFC}$ 파일에서 필요한 정보를 추출할 수 있도록 메타 데이터(Metadata)만 관리하도록 한다. 메타데이터는 IfcPropertySet에서 유즈케이스 관점에 따라 필요한 정보를 CityGML관점에서 추출할 수 있도록, UsecasePerspective를 추가하고, 여기에 맵핑 사전 (Mapping Dictionary)를 정의하였으며, 실제 메타데 이터는 이를 참조하도록 한다. 또한 IfcModelLink를 통해 IFC파일을 얻을 수 있도록 URL를 관리하며, $\mathrm{IFC}$ 파일이 CityGML과 동일한 좌표계에 놓이도록 좌표변환행렬을 참조하도록 한다. 이를 표현한 구조 는 다음과 같다.

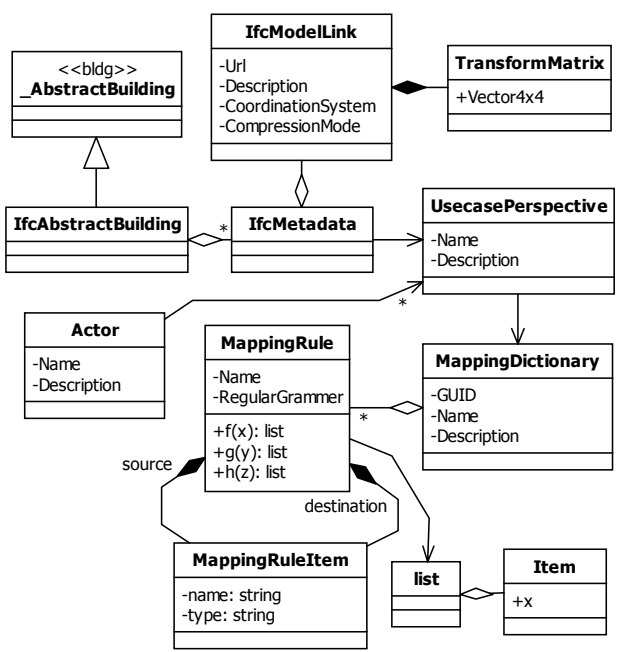

그림 14. 제안된 $\mathrm{IFC}$ 참조 모델

맵핑 사전은 맵핑 규칙을 포함하는 데, $\mathrm{IFC}$ 와 CityGML간에 맵핑하는 속성 정보의 종류, 개수가 다르기 때문이다. 이런 규칙을 정의하기 위해 다음 과 같이 정의한다.

$$
\begin{aligned}
& h \circ g_{b} \circ f_{a}(x)=h\left(g_{b}\left(f_{a}(x)\right)\right) \\
& f: I \rightarrow G \\
& I=\left\{I_{i} \mid 0<i<n, \text { parameters of IFC }\right\} \\
& I_{\text {sub }}=\{x \mid x \subset I\} \\
& \quad G=\left\{G_{j} \mid 0<j<m, \text { parameters of City } G M L\right\} \\
& \\
& \text { parameters }=\{\text { parameter }\} \\
& \text { parameter }=\{\text { name }, \text { type }, \text { value }\} \\
& \text { type }=\{\text { vmber, string, stringlist }\}
\end{aligned}
$$


$f_{a}(x)$ 는 맵핑 규칙을 정의한 함수이며 아래와 같다.

표 4. $f_{a}(x)$ 정의

\begin{tabular}{|l|ll|}
\hline$a$ & \multicolumn{1}{c|}{ Function } \\
\hline 1 & $I_{i} \rightarrow G_{j}$ & \\
\hline 2 & $I_{\text {sub }} \rightarrow G_{j}$ & \\
\hline
\end{tabular}

$g_{b}(y)$ 는 type 변환 규칙을 정의한 함수이며 아래와 같다.

표 5. $g_{b}(y)$ 정의

\begin{tabular}{|c|c|c|}
\hline$b$ & Function & Example \\
\hline 1 & 함수 입력 그대로 출력 & $\{123\} \rightarrow\{123\}$ \\
\hline 2 & $\begin{array}{l}\text { type이 숫자이면 문장열로 } \\
\text { 변환 }\end{array}$ & $\{123\} \rightarrow\left\{" 123^{\prime \prime}\right\}$ \\
\hline 3 & $\begin{array}{l}\text { type이 문자열이면 숫자로 } \\
\text { 변환 }\end{array}$ & $\{" 123 "\} \rightarrow\{123\}$ \\
\hline 4 & $\begin{array}{l}\text { type이 문자열 집합이면 } \\
\text { ',로 구분된 문자열리스트 } \\
\text { 로 변환 }\end{array}$ & $\begin{array}{l}\{" 123 ", \quad " 456 ") \rightarrow \\
\left\{" 123,456^{\prime \prime}\right\}\end{array}$ \\
\hline
\end{tabular}

$h(z)$ 는 value 변환 규칙을 정의한 함수이며, regular grammar에 따라 변환된다. 이런 규칙이 포함된 변 환 함수를 이용해, 각 유즈케이스 별로 필요한 정보 를 $\mathrm{IFC}$ 에서 추출하여, Actor가 Query시 정보를 적 절히 추출할 수 있다.

\section{6. 결 론}

본 연구는 $\mathrm{BIM}$ 과 $\mathrm{GIS}$ 간 정보 상호운용성을 연구 하기 위해, 이와 관련된 연구 동향을 조사한 후 $\mathrm{BIM}$ 과 GIS간의 상호운용성과 관련된 유즈케이스 를 고찰하고 각 분야의 대표적인 중립 모델인 IFC(Industry Foundation Class)와 CityGML의 구 조적 특징과 공통 구조를 살펴보았다. 이 후 이런 문제에 대한 다른 접근법으로 $\mathrm{IFC}$ 와 CityGML이 공통적으로 겹쳐지는 부분에 대해 확장한 후, 확장 된 클래스에 메타데이타를 정의하여, 유즈케이스에 서 필요한 정보만 $\mathrm{CityGML}$ 에서 $\mathrm{IFC}$ 로 정보 질의 를 지원 하도록 $\mathrm{IFC}$ 에서 CityGML로 맵핑할 수 있 는 구조와 맵핑 규칙 함수를 제안하였다.

다만, 본 제안 모델에서는 캐쉬 기법과 같이 맵핑 되어 추출된 속성들을 보관하여 빈번한 정보 쿼리 시 빠르게 처리하거나, 추출된 속성들을 압축하여
파일 크기를 줄이는 등의 압축 기법은 고려하지 않 았다. 이에 관한 연구가 필요하다.

\section{참 고 문 헌}

[1] CityGML UML diagrams as contained in CityGML Encoding Standard Version 1.0.0, OGC

[2] IFC2x4, BuildingSmart, http://www.buildingsmart-tech.org/ifc/IFC2x4/alpha/html/index.htm

[3] I-Chen $\mathrm{Wu}$ and Shang-Hsien Hsieh, 2007, "TRANSFORMATION FROM IFC DATA MODEL TO GML DATA MODEL: METHODOLOGY AND TOOL DEVELOPMENT", Journal of the Chinese Institute of Engineers, Vol. 30, No. 6, pp. 1085-1090.

[4] Ihab Hijazi, Manfred Ehlers, Sisi Zlatanova, Umit Isikdag, "Institute for Geoinformatics and Remote Sensing”, University of Osnabruck, Osnabruck, Germany.

[5] Leon van Berlo, Ruben de Laat, 2010, "Integration of BIM and GIS: The development of the CityGML GeoBIM extension”, International 3D GeoInfo Conference.

[6] Nagel C, Stadler, A, Kolbe T, 2009, "Conceptual Requirements for the Automatic ReBIM / VDCruction of Building Information Models from Uninterpreted 3D Models, Academic Track of Geoweb 2009 Conference”, Vancouver.

[7] 고일두, 최중현, 김이두, 정연석, 이재민, 2008, "BIM으로부터 가상도시 구축용 건축물정보의 추 출", 한국공간정보학회지, 제 16 권, 제 2 호, $\mathrm{pp}$. 249-261.

[8] 김인한, 2009, “유비쿼터스 도시에서의 BIM", 대한건축학회지, 제 53 권, 제1호, pp. 27-30.

[9] 김이두, 고일두, 2011.6, "건물상세정보를 포함한 3-D GIS용 캠퍼스 모델의 구축”, 한국도시설계 학회지, 제 12 권, 제 3 호, pp. 15-26.

[10] 신인수, 김정준, 장택수, 한기준, 2012.2, "USN 환경을 위한 공간 센서 데이터베이스 시스템의 설계 및 구현”, 한국공간정보학회지, 제 20 권, 제 1호, pp. 59-69. 
논문접수 : 2012.09.09

수 정 일 : 2012.10.25

심사완료 : 2012.10.30

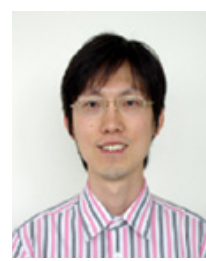

강 태 욱

2005년 숭실대 소프트웨어공학 공학석 사

2009년 중앙대 건설환경공학 공학박사 2010년 2011년 중앙대 건설환경공학

2011년 2012년 (주)한길아이티 BIM사업본부장

2012년 현재 한국건설기술연구원 수석연구원

관심분야는 $\mathrm{BIM}, \mathrm{CAD}$, GIS, 데이터 마이닝, Media art

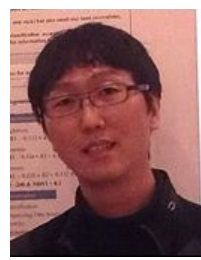

홍 창 희

1997년 인하대학교 공학사

1999년 인하대학교 대학원 공학석사

2006년 서울대학교 대학원 공학박사수 료

1999년 현재 한국건설기술연구원 수 석연구원

관심분야는 3차원 공간정보, $\mathrm{BIM} / \mathrm{GIS}, \mathrm{u}-\mathrm{City}$

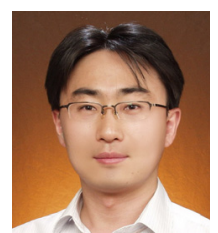

황 정 래

2007년 부산대학교 대학원 지형정보공 학과 공학박사

2008년 2009년 부산대학교 컴퓨터 및 정보통신연구소

기금교수

2008년 현재 한국건설기술

연구원 ICT융합연구실 수석연구원

관심분야는 공간데이터모델, 3 차원 공간정보,

$\mathrm{BIM} / \mathrm{GIS}$

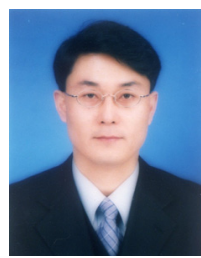

최 현 상

1998년 경북대학교 대학원 공학석사 2002년 경북대학교 대학원 공학박사 2002년 현재 한국건설기술 연구원 연 구위원

2010년 현재 한국공간정보학회 상임

이사

관심분야는 3 차원 공간정보, $\mathrm{BIM} / \mathrm{GIS}, \mathrm{u}-\mathrm{City}$ 